\title{
A IMPORTÂNCIA DO ECOSSISTEMA EMPREENDEDOR PARA A ECONOMIA SOCIAL E SOLIDÁRIA (ESS): AVANÇOS, RETROCESSOS E DESAFIOS ATUAIS NO BRASIL
}

THE IMPORTANCE OF THE ENTREPRENEURIAL ECOSYSTEM FOR THE SOCIAL AND SOLIDARITY ECONOMY (SSE): ADVANCES, SETBACKS AND CURRENT CHALLENGES IN BRAZIL

\section{RESUMO}

Leandro Pereira Morais ${ }^{1}$ Miguel Juan Bacic ${ }^{2}$

O artigo discute o estado da arte da construção do "ecossistema empreendedor" para a Economia Social e Solidária (ESS), visto que a formação de tal ecossistema é a peça fundamental para a emancipação e para o fortalecimento dos Empreendimentos Econômicos Solidários (EES). A construção do ecossistema empreendedor solidário constitui-se uma tarefa complexa, marcada por inúmeros desafios, sobretudo quando se aliam a esta construção, algumas fragilidades estruturais dos EES inerentes ao seu modus operandi. O artigo analisa o constructo ecossistêmico empreendedor para a ESS em alguns países da Europa e Ásia, finalizando com o caso brasileiro.

Palavras-chave: Ecossistema empreendedor solidário. Economia social e solidária. Empreendimentos econômicos solidários.

\begin{abstract}
The objective of this article is to discuss the state of the art of the construction of the "entrepreneurial ecosystem" for the Social and Solidarity Economy (SSE), considering the formation of the ecosystem the fundamental piece for the emancipation and for the strengthening of Solidarity Economy Enterprises (SEE). The construction of the entrepreneurial solidarity ecosystem is a complex task, facing many challenges, especially when this construction is combined with some structural weaknesses inherent to its modus operandi. The article analyses the entrepreneurial ecosystem construct for SSE in some countries from Europe and Asia, ending with some considerations on the Brazilian case.
\end{abstract}

Keywords: Solidarity entrepreneurial ecosystem. Social and solidarity economy. Solidarity economy enterprises

\section{INTRODUÇÃ̃O}

Um dos grandes desafios para a criação, a manutenção e o fortalecimento dos Empreendimentos Econômicos Solidários (EES) é o estabelecimento efetivo de um ecossistema empreendedor para a Economia Social e Solidária (ESS). Entende-se que a formação do ecossistema empreendedor para a ESS é peça fundamental para a emancipação dos EES (MORAIS; BACIC, 2016).

\footnotetext{
${ }^{1}$ Professor Doutor do Departamento de Economia da UNESP-ARARAQUARA. E-mail: lpmorais@ fclar.unesp.br

${ }^{2}$ Professor Titular do Instituto de Economia da UNICAMP. E-mail: bacic@.unicamp.br
} 
Nota-se que um dos grandes problemas dos EES é que a construção do "espaço emancipador" ou do "espaço de autonomia" tem como pré-requisito competências e recursos que não estão ao alcance da maioria das pessoas que participam dos grupos autogestionários. Por esta razão não é possível uma cópia pura e simples das instituições que atuam dentro do ecossistema empreendedor que envolve as empresas tradicionais, quando se pensa a articulação de um conjunto de instituições e atores que ajam em favor das ESS, uma vez que estas possuem características específicas, com implicações socioeconômicas, políticas e culturais em seus territórios, diferentes daquelas que podem ser encontradas nas empresas tradicionais (MORAIS, 2013; BACIC, 2014).

Por outro lado, observa-se, entre as lideranças de alguns EES, certa resistência - real, simbólica ou até mesmo ideológica - em discutir temas mais estritamente econômicos e financeiros, como: custos de produção, custos do empréstimo, estratégias de mercado, excedente produtivo etc.

Segundo Gaiger (2008), mesmo os intelectuais que debatem a ESS apresentam resistência à discussão dos temas relacionados ao funcionamento da empresa, eficiência e empreendedorismo, dado que teriam um olhar ideológico que dificultaria aceitar que os EES devam atuar dentro de princípios de racionalidade capitalista. Este autor também propugna a necessidade de resgatar o termo "empreendedorismo" no âmbito da ESS, além de entender a complexidade do processo empreendedor e sua adequação às necessidades de um "empreendedorismo associativo", típico dos EES, para o qual são ingredientes necessários: a cooperação no trabalho, as decisões coletivas, a troca de informações e um projeto coletivo.

Nesse sentido, este artigo tem como intuito discutir o estado da arte da construção do ecossistema empreendedor para a ESS. Para tal, o artigo estrutura-se em três seções, além desta introdução e da conclusão, sendo na primeira seção discutidos alguns aspectos do processo empreendedor, para na seção seguinte apresentar a ideia presente no modelo da "Hélice Tripla". Em seguida, na terceira seção, foi abordado o constructo ecossistêmico empreendedor para a ESS em alguns países, finalizando com um tópico dedicado a considerações sobre o caso brasileiro.

\section{PROCESSO E ECOSSISTEMA EMPREENDEDOR}

Um ecossistema empreendedor é uma comunidade dentro de uma região de atores interdependentes, com papéis diversos que interagem, determinando o desempenho do ecossistema e, eventualmente, de toda a economia de uma região (SPILLING, 1996). Como resultado do desempenho do ecossistema espera-se que, além dos resultados obtidos pelas empresas e pelas organizações componentes (em termos de desempenho e aprendizado), a interação leve à geração de novas empresas. Os ecossistemas empreendedores podem produzir impacto favorável na macroeconomia da região e, quando se sustentam ao longo do tempo, atraem novos atores que dinamizam o desempenho do ecossistema (por exemplo, empresas ou fundos que se dedicam a financiar start-ups, o que pode contribuir com o aparecimento de maior número de empresas nascentes).

Os elementos que fazem parte de um ecossistema empreendedor são de natureza institucional e relacional e estão inseridos dentro de um ambiente natural e social. Cohen (2006) distingue os elementos da rede formal dos da rede informal, sendo:

A. Rede informal: composta por amigos, colegas e familiares dos empreendedores e suas eventuais relações com outras empresas em condição semelhante às que estão criando ou dirigindo. 
B. Rede formal: constituída por uma diversidade de atores, como as universidades de pesquisa, os serviços de apoio do governo local, regional ou nacional, os serviços de apoio empresarial (consultores, contadores, advogados), provedores de capital (bancos, investidores anjos - capital semente), investidores de risco, empresas formais de grande e médio porte. brasileiro.

A seguir, são descritos alguns elementos da rede formal, em conformidade ao caso

Universidade de pesquisa: sua importância se deve ao seu potencial para a criação de novas tecnologias e por permitir a combinação do conhecimento de diversas áreas..Kantis (2017), ao relatar o surgimento do Silicon Valley, afirma que um elemento muito importante para o surgimento desse ecossistema foi a existência de uma universidade como a de Stanford, além da existência de um empreendedor institucional que atuava nela (no caso, o Professor Lewis Terman, com experiência no Massachusetts Institute of Technology - MIT). Segundo a Carnegie Foundation for the Advancement of Teaching, um indicador para qualificar uma universidade de pesquisa seria ter 15 programas de doutorado e a formar ao menos 50 doutores por ano. No Brasil, 23 universidades cumprem estes requisitos (Lemos, 2011). Algumas dessas universidades possuem projetos próprios de parques tecnológicos, bem como ações voltadas às incubadoras tecnológicas de cooperativas populares.

Governo: pode criar um clima favorável aos empreendedores, diminuir impostos e burocracia e criar programas favoráveis ao surgimento e funcionamento dessas empresas. Kantis (2017), ao descrever a origem do ecossistema empreendedor nos Estados Unidos e em Israel, afirma que o governo possui um importante papel no processo de emergência deste ecossistema, levando em conta a concessão de recursos financeiros para o fomento de pesquisas iniciais, de pesquisas tecnológicas e de inovação, bem como no aporte à infraestrutura básica que propicie melhores condições de competitividade aos territórios. No caso brasileiro, existem agências governamentais (como por exemplo: a Financiadora de Estudos e Projetos (FINEP); o Conselho Nacional de Pesquisa e Desenvolvimento Científico e Tecnológico (CNPq); a Fundação de Amparo à Pesquisa do Estado de São Paulo (FAPESP); o Banco Nacional de Desenvolvimento Econômico e Social (BNDES) etc.), que possuem programas de apoio para os empreendedores, a partir de concessão de bolsas, aporte de capital e fomento ao capital de risco. O governo federal (e também alguns estaduais, como o de São Paulo) possuem projetos para o desenvolvimento de parques tecnológicos. Citam-se, adicionalmente, algumas leis, tais como: a Lei do Supersimples (2007) - regime que facilita o pagamento de impostos (um único pagamento mensal) com taxas reduzidas; a Lei Geral da Micro e Pequena Empresa (2006) que facilita a contabilidade, o acesso ao crédito e a participação nas compras governamentais.

Rede de Serviços e Apoio: consiste num conjunto de atores que oferecem serviços profissionais de apoio às empresas provedoras de insumo. No Brasil, o Serviço Brasileiro de Apoio às Micro e Pequenas Empresas (SEBRAE) é a instituição que oferece a mais ampla gama de serviços de apoio aos pequenos e médios empreendedores tradicionais.

Fontes de Capital: fontes de recursos para as empresas nascentes seja na forma de capital de risco, seja como capital semente. No Brasil, as linhas de crédito são estreitas e de acesso competitivo para as empresas incubadoras ou em início de operação.

Talentos humanos: empresas e incubadoras de base tecnológica costumam surgir em locais onde existem universidades, por contarem com recursos e pessoas qualificadas para atenderem suas necessidades e com capacidade para inovar projetos de negócio, que, inclusive, poderão originar novas empresas. 
Empresas constituídas: as empresas já constituídas podem ter um papel na formação das habilidades empreendedoras, a partir do treinamento e da experiência que algumas pessoas ganham em seu interior e que, posteriormente, originam as spin-offs. As empresas constituídas podem ser clientes importantes das empresas nascentes. As empresas nascentes tendem a localizar-se em regiões onde há universidades, dada a maior oferta de pessoas qualificadas.

Incubadoras: as incubadoras de empresas são muito importantes como elemento de apoio às empresas nascentes e podem ter sua sede dentro de uma universidade ou dentro de dependências facilitadas por uma municipalidade ou por algum programa de governo estadual ou federal. Kantis (2017), ao abordar o surgimento do ecossistema empreendedor em Israel, menciona como exemplo o interessante programa "Incubadoras 2.0", uma experiência, operada pelo governo, que relaciona fundos públicos e privados. Através deste programa é organizado um concurso pelo qual são selecionadas propostas institucionais apresentadas por empresas locais, bem como é estimulado o investimento de fundos estrangeiros de grandes empresas que tenham interesse nesse tipo de empreendimento de incubação. As empresas incubadas pelo programa que obtêm "sucesso" retornam este investimento a partir do pagamento de royalties, que variam entre 3 a 5\% das vendas, até o reembolso do subsídio aplicado. No Brasil, existem redes de incubadoras por estado que se organizam dentro de uma rede nacional. Além da infraestrutura física, oferecem serviços administrativos e de consultoria. O SEBRAE apoia financeiramente e com consultorias as incubadoras e as empresas incubadas. A Associação Nacional de Entidades Promotoras de Empreendimentos Inovadores (ANPROTEC) representa os interesses das incubadoras, parques tecnológicos e empresas inovadoras do Brasil.

No Brasil, tanto o processo empreendedor, como seu ecossistema, tendem a ser avaliados como frágeis e sujeitos a melhorias. Um indicador permanentemente monitorado é o da taxa de sobrevivência das empresas após dois anos de vida, que segundo dados do Sebrae (2016) é de 76,6\%. Este indicador melhorou sensivelmente ao longo dos últimos anos em função de diferentes fatores, dentre os quais, a ação do SEBRAE e a melhoria do ambiente regulatório (Lei do Supersimples, Lei Microempreendedor Individual).

Tendo como base os conceitos de processo e ecossistema empreendedor para os empreendimentos de base empresarial, cabe refletir sobre o ecossistema empreendedor para os empreendimentos de economia solidária (EES), tendo em vista as características do empreendedor deste segmento.

Interessante contribuição para a sistematização da estrutura deste processo pode ser vista em estudos realizados pela Comunidade Europeia (2016) e, na perspectiva asiática, em estudos sobre o caso sul-coreano (Kim; Jung, 2016), que serão detalhados posteriormente.

A partir desses estudos, entende-se como uma estrutura coerente de organização do processo ecossistêmico empreendedor solidário, deve ser composta pelos seguintes elementos: a) Conhecimento; b) Acesso aos mercados; c) Suporte público e fiscal para start-ups de ESS; d) Acesso ao financiamento; e) Instrumentos de apoio às redes e suporte mútuo e f) Desenvolvimento de pesquisas e de qualificação na área. Importante incluir nessa estrutura a capacidade de criar indicadores de avaliação e monitoramento dos EES; tarefa árdua e complexa, porém de extrema relevância e que se refere a um dos maiores desafios do século XXI.

Nesta perspectiva, uma das maneiras de se enfrentar tamanho desafio concernente à estruturação destes componentes é aliar esforços e responsabilidades de construção conjunta entre os EES, a universidade e o governo, através de políticas públicas (esta, necessariamente em processo de construção entre os agentes). Tal assertiva merece ser melhor explorada, a partir do modelo da "Hélice Tripla". 


\section{A COMPOSIÇÃO DO ECOSSISTEMA EMPREENDEDOR SOLIDÁRIO: O PAPEL DA "HÉLICE TRIPLA"}

Ao tratar da importância dos empreendimentos, da universidade e da política pública na composição do ecossistema empreendedor solidário, chega-se à ideia da relevância em se atingir o "potencial sinérgico", para articular e integrar a Hélice Tripla ${ }^{3}$ (Etzkowitz, Leydesdorff (1995). em prol do ecossistema empreendedor solidário.

Conforme nos aponta Lemos (2011):

[...] para que o tratamento dos ecossistemas se mostre como abordagem viável ao planejamento e a gestão estratégica do empreendedorismo, é importante apresentar as razões que fazem da hélice tripla uma visão e prática predominantes. (LEMOS, 2011, p. 44).

Em seu trabalho, observam-se algumas razões, dentre elas: i) a abordagem da Hélice Tripla combina economia com importante conteúdo sociológico dos sistemas de inovação, o que seria uma característica distintiva desta perspectiva; ii) a abordagem da Hélice Tripla tem uma destinação à aplicação em políticas públicas e de seu gerenciamento em instituições de pesquisa, em universidades e em organismos internacionais; iii) tal abordagem funciona como facilitadora do planejamento, gestão e execução em processos de tomada de decisões e em avaliações dessas políticas.

Na abordagem da Hélice Tripla três "ativos críticos" são considerados relevantes para o desenvolvimento do ecossistema empreendedor: a) ativos voltados às atividades inovadoras; $b$ ) ativos para ações empreendedoras e, c) ativos-ponte, que seriam formados por pessoas e mecanismos responsáveis pela indução e coordenação da interação entre os empreendedores e o conhecimento.

Além do exposto, a abordagem Hélice Tripla: a) está focada em um "modelo bottomup", visto que os sistemas devem ser pensados em direção à valorização das pessoas e dos grupos relacionados; b) entende como importante a capacidade de orquestração e articulação (de natureza transversal), como forma de caracterização das diretrizes teóricas desta metodologia; c) se apoia na visão ecológica de sistemas e de redes, não pela via da "seleção natural", mas a partir das considerações das interações (ecológicas e evolutivas) que integram todo o ecossistema, todas as espécies e todos os organismos de um determinado hábitat e o seu meio ambiente físico.

Tais premissas permitem emergir a ideia de "coevolução", quando organizações podem interagir com seus ecossistemas e os ecossistemas interagem com as organizações. Ainda segundo Lemos (2011), é necessário salientar que a coevolução é um conceito transversal, que atua tanto em nível micro quanto em nível macro e que se mostra peça chave no desenvolvimento da perspectiva ecossistêmica. Em outros termos, é necessário considerar que organizações podem apresentar coevolução em instâncias mais amplas, como por exemplo, em relação a trajetórias tecnológicas, ao ambiente social, regulatório e institucional. Ou seja, é uma evolução conjunta com o ambiente em que estão inseridas e integradas.

Adicionalmente, o que vai fazer com que a liderança do ecossistema se mantenha depende da capacidade da organização(ões) líder(es) de convencer os componentes do ecossistema de que vale a pena continuar evoluindo em conjunto, ou seja, coevoluindo.

\footnotetext{
3 Este modelo pressupõe uma relação de cooperação e entrelaçamento entre 3 atores essências para o desenvolvimento da inovação: o setor público, o setor privado e a academia. Essa relação leva a criação de organizações híbridas, como centros de pesquisa cooperativos, institutos, incubadoras e parques tecnológicos.
} 
Portanto, a vitalidade coletiva (e não individual) do ecossistema é condição de sua própria sustentabilidade, manutenção e evolução. Ao invés de focar apenas nas suas competências, recursos e capacitações internas, os envolvidos devem saber das interdependências entre os organismos dos ecossistemas e enfatizar as propriedades coletivas das redes de negócios e ecossistemas dos quais participam (IANSITI; LEVIEN, 2004).

Outro elemento fundamental da construção ecossistêmica é o grau de interconectividade, ou seja, de interdependência que todos os componentes do sistema guardam entre si. Para Lemos (2011, p. 59):

Essa interdependência é como uma cadeia trófica - garante a produtividade, a criatividade e a estabilidade do ecossistema. Por isso algumas espécies são beneficiárias dos inputs de outras e conseguem com isso concentrar nas suas atividades, sem ter que produzir elas próprias esses inputs de que fazem uso e são dependentes. As espécies-chave são verdadeiras plataformas para outras espécies. Sua diminuição ou desaparecimento causa desequilíbrios profundos ou até mesmo o desaparecimento do ecossistema. Essas são as espécies que definem, que dão o tom da vitalidade (health) do ecossistema.

Neste sentido, entende-se que a necessidade da construção de um processo que se deve permear por uma perspectiva "bottom-up" e de transversalidade, possibilitando a coevolução na direção de uma "vitalidade coletiva" e com graus de interconectividade, encontra terreno fértil nos EES. Ainda que, com fragilidades estruturais, os EES imbuídos de elementos da ESS permitem o aparecimento e o fortalecimento, em seu modus operandi, dessas características sugeridas para a construção de ecossistemas empreendedores solidários.

\section{O CONSTRUCTO ECOSSISTEMICO EMPREENDEDOR PARA A ESS}

Conforme o que fora exposto anteriormente, percebe-se que a construção do ecossistema empreendedor constitui-se uma tarefa complexa e marcada por inúmeros desafios. Assim como já mencionado, tais desafios decorrem do reconhecimento desse conceito como algo sistêmico e dinâmico. Quando especificamente se trate do ecossistema empreendedor para a ESS, tais complexidade e desafios se intensificam, tendo em vista as próprias fragilidades estruturais inerentes que caracterizam a ESS, bem como o campo ainda aberto de institucionalização de suas políticas (MORAIS, 2013; MORAIS; BACIC, 2016).

De maneira geral, conforme sistematizado por Serrano (2015, p. 173), os ecossistemas são "redes de atores" (pessoas empreendedoras, pesquisadores, financiadores, políticos executivos e legislativos etc.) que levam em conta as dimensões física-territorial e cultural do território em questão; território este marcado por um conjunto de sistemas, tais como: a) sistemas políticos (alianças e coalizões entre os atores sociais e os atores políticos que constituem a base para a governança territorial); b) sistemas de produção (que induzem à criação de redes de atores envolvidos na produção de bens e de serviços) e c) sistemas territoriais de inovação (criados por alguns grupos de atores envolvidos com a geração e a difusão de inovação). Tais sistemas perfazem um "componente físico" com consequências sociológicas, políticas e econômicas. Ainda para este autor, o constructo ecossistêmico deve também levar em conta a necessidade da promoção da "auto reflexão", ou seja, ser capaz de se analisar de forma "endogâmica", a partir da pesquisa, da criação de estatísticas e de análises de impacto, bem como da necessidade da abertura e do estreitamento de laços com os movimentos sociais. 
Em termos práticos, já há exemplos em alguns lugares do mundo que podem nos auxiliar e inspirar. A seguir, apresentam-se algumas informações acerca dos casos europeu e asiático, regiões onde já há certo avanço na consecução e registro do ecossistema empreendedor para a ESS.

\section{a. O CASO EUROPEU}

O estudo "Social enterprises and their eco-systems: developments in Europe" (EUROPEAN COMMISSION, 2016), reconhecendo a complexidade inerente ao processo de constituição do ecossistema para as empresas sociais, propugna a existência de dois pilares fundamentais: políticas públicas de apoio e capacidade auto-organizativa da sociedade civil.

Este estudo, tendo como cerne os elementos acima descritos (políticas públicas de apoio e capacidade auto-organizativa da sociedade civil), propõe uma estrutura para se alcançar a composição do ecossistema, que inclui: a) conhecimento - sensibilização política e formas legais de reconhecimento destas políticas e ação; b) acesso aos mercados; c) suporte público e fiscal para start-ups de ESS; d) acesso ao financiamento; e) instrumentos de apoio às redes e suporte mútuo; f) desenvolvimento de pesquisas e qualificação na área. Segundo o estudo da Comissão Europeia: "Os relatórios nacionais confirmam que, mais do que depender de apenas um fator, o ecossistema é moldado pela interação entre todos esses fatores " 4 (EUROPEAN COMMISSION, 2016, p. 19, tradução nossa).

Uma análise mais detalhada da estrutura de construção do ecossistema empreendedor solidário (ou de empresas sociais, no caso específico da União Europeia), nos traz algumas informações interessantes.

Em relação ao primeiro ponto (conhecimento - sensibilização política e formas legais de reconhecimento destas políticas), dependendo do país, tal reconhecimento se dá a partir de diferentes instrumentos, como por exemplo: leis específicas para as empresas sociais (caso do Reino Unido) ou para a ESS (casos da Espanha e Itália); criação de ministérios, secretarias ou departamentos pertinentes ao tema (casos da Bulgária com o National Social Economy Concept e da Polônia com o National Programme for Social Economy Development); elaboração de documentos oficiais ressaltando o papel dos programas de fortalecimento da ESS.

No que se refere ao acesso aos mercados, segundo ponto da estrutura construtiva do ecossistema social europeu, as empresas sociais e/ou de ESS, possuem produtos e serviços que podem ser direcionados à demanda do setor público e privado. Desta forma, verificam-se políticas públicas ou programas de fortalecimento a estes empreendimentos, sobretudo, em três frentes, a depender do país: promoção, integração ou substituição (de serviços antes ofertados pelo Estado e que passam a ser proporcionados por empresas sociais, como, por exemplo, serviços de apoio ao idoso ou às crianças, serviços de desenvolvimento comunitário etc.). Um fator importante para o fortalecimento dessas medidas foi a criação do EU Public Procurement Rules, de 2014, regulação esta que objetiva oferecer novas oportunidades e estímulos à criação de empresas sociais, mormente as voltadas à provisão de serviços sociais e de saúde. Vale mencionar que, a partir de maio de 2016, 21 Estados Membros se dispuseram a iniciar e adequar-se a essa importante regulação em nível europeu. Como exemplo, podem-se citar países como França, Irlanda, Itália, Polônia e Eslováquia que introduziram aspectos desta

\footnotetext{
4 "National reports confirm that, rather than depending upon one factor alone, the eco-system is shaped by the interplay between all these factors."
} 
regulação em suas respectivas legislações nacionais, entre 2015 e 2016. Nesta perspectiva, vale mencionar também as políticas de "reserva de mercado" para algumas empresas sociais, reconhecidas por lei, como na Itália e na Eslováquia, que garantem a inserção de trabalhadores descapacitados física e mentalmente.

O terceiro ponto da estrutura trata do suporte público e fiscal para start-ups de ESS. Em todos os países analisados, observa-se que a estrutura fiscal inserida no campo da ESS é complexa, heterogênea e fragmentada. Tal fato se deve, inclusive, à heterogeneidade de organizações que compõem a ESS (cooperativas, associações, fundações, empresas sociais etc.). Em geral, os acordos fiscais voltados a essas organizações são classificados em três tipos: a) contribuições para a seguridade social reduzidas (reduced social security contributions); b) isenção de impostos e taxas mais baixas (tax exemptions and lower rates) e c) reduções fiscais para os doadores privados ou institucionais (tax reductions for private and or institutional donors). Na Bélgica, por exemplo, há redução da contribuição social de organizações que atuam com serviços sociais e de saúde, enquanto que na França, associações que promovem atividades culturais e esportivas estão isentas de impostos sobre o valor agregado que recaem sobre suas atividades (Value Added Tax - VAT). Já na Irlanda, as associações de caridade, que podem incluir algumas empresas sociais, são menos tributadas. Na Itália, as cooperativas sociais são isentas do corporate tax (IRES), além de possuírem tratamento especial em relação ao VAT, enquanto que na Espanha, as cooperativas sociais são tributadas em $20 \%$ (e não 30\%, como as demais empresas) em relação às corporate taxes e possuem uma redução de $95 \%$ na tributação sobre suas atividades econômicas (activity tax).

No que tange especificamente ao suporte para as start-ups, as medidas de apoio se diferem entre os governos (central e regional) e os tipos de empresas. Alguns países como Bélgica, França, Itália, Polônia e Espanha reconhecem a importância da cooperação estreita com as autoridades locais para o desenvolvimento da ESS. A região administrativa AuvérniaRódano-Alpes (antiga Ródano-Alpes), na França, é um exemplo evidente de uma região que impulsiona sistematicamente a ESS. Na Irlanda, a origem do suporte público para a ESS se deu, a partir de 2000, através do Social Economy Programme e do Community Services Programme.

$\mathrm{O}$ acesso ao financiamento compõe o quarto ponto da estrutura do constructo do ecossistema europeu para a ESS e é considerado como uma questão estratégica. Em face da já mencionada heterogeneidade das organizações que compõem a ESS, cada organização apresenta facilidades e dificuldades no que diz respeito ao financiamento. Algumas delas apresentam mais facilidades em autofinanciamento (self-financing abilities), tendo em vista a significativa escala de doações de seus voluntários. Outras organizações dependem fortemente de crédito público ou de bancos específicos (voltados às cooperativas, à área rural, habitação etc.) de apoio à realização de suas atividades.

De maneira geral: i) os instrumentos financeiros que apoiam inovações sociais são mais recentes e vêm apresentando crescente importância e atenção. Como exemplos, citam-se: impact investing; social impact bonds; social venture capital; crowdfunding etc.; ii) as principais dificuldades para o acesso a financiamento encontradas através dos estudos sobre países referem-se à ausência de "tino investidor", bem como à falta de habilidades para desenvolver projetos adequados e, consequentemente, passíveis de serem financiados. Nesse sentido, o estudo da União Europeia chama atenção ao fato de que "há necessidade de políticas adequadas que sejam capazes de incentivar a capitalização das empresas sociais por meio de instrumentos de financiamento inovadores"5 (EUROPEAN COMMISSION, 2016, p.36, tradução nossa).

\footnotetext{
5 "There is a need for adequate policies that are able to incentivize social enterprise capitalization by means of innovative financing tools."
} 
As redes e os mecanismos de suporte mútuo são outro ponto fundamental na estrutura do ecossistema europeu para a ESS. Onde estes elementos existem, as chances de êxito da ESS são bem superiores comparativamente aos casos em que não se verifica o estabelecimento de redes e mecanismos de apoio mútuo entre os empreendimentos. Adicionalmente, as redes permitem replicar experiências positivas em termos econômicos, sociais e políticos. Ao analisar os países europeus, o estudo afirma que as redes: "desempenharam um papel importante na legitimação da emergência de um novo tipo de cooperativa, com um objetivo social explícito, e fizeram um lobby bem sucedido pela introdução de políticas de apoio através da participação na elaboração de novas legislações e políticas públicas" 6 (Idem, p. 37, tradução nossa), assim como ocorrera na França (Les Scop, network of SCOPS), na Itália (Confcooperative e Forum del Terzo Settore) e na Espanha (CEPES).

Por fim, não menos importante, aparece na estrutura de construção do ecossistema europeu para a ESS, os temas concernentes à educação e à qualificação ou ao desenvolvimento de capacidades e de conhecimento em determinadas áreas ("skills development"). Na visão do estudo, esta temática configura-se como "um novo campo de investigação científica" (EUROPEAN COMMISSION, 2016, p. 39 tradução nossa) ${ }^{7}$, ainda que "embora esteja atraindo o interesse de um número crescente de pesquisadores, a pesquisa nesta área ainda é fragmentada e frequentemente utiliza um único método, geralmente descritivo e classificatório" (Ibid, tradução nossa) ${ }^{8}$. Tal reconhecimento decorre também do fato de que a ESS não é regulada por uma só legislação, mas por várias legislações (quando existem) que variam por tipo de organização e ou por país de atuação.

No entanto, deve-se frisar que "o número de programas educacionais e de treinamento moldados para empresas sociais está também crescendo significativamente" (Ibid, tradução nossa) ${ }^{9}$. Na França, por exemplo, os módulos de estudos ligados à ESS estão integrados aos programas de nível universitário, contabilizando no país, em 2012, segundo dados fornecidos pelo estudo europeu, mais de 70 cursos relativos à ESS. Nesse país há também uma rede interuniversitária (RIUESS) de professores e pesquisadores especializados na ESS. Também, na Bélgica e na Itália, diversas universidades incluíram em seus cursos disciplinas na área de ESS e temas afins.

Em se tratando do desenvolvimento de capacidades e de conhecimentos ("skills development"), o estudo europeu nos mostra que:

Em todos os países estudados, incluindo aqueles onde as empresas sociais cresceram em número e tamanho e provaram ser provedores eficientes de um amplo conjunto de serviços de interesse geral, a gerência continua sendo uma área de debilidade. Isso é devido principalmente ao fato de que muitas empresas sociais se desenvolveram a partir de grupos comunitários. Consequentemente, elas ainda são conduzidas, em grande parte, por voluntários ou podem não ter habilidade para recrutar funcionários que tenham habilidades gerenciais específicas. ${ }^{10}$ (EUROPEAN COMMISSION, 2016. p.40, tradução nossa).

\footnotetext{
6 "Have played an important role in legitimizing the emergence of a new type of cooperative, with a declared social aim, and they have successfully lobbied for the introduction of enabling policies by participating in the drafting of new legislation and policies."

7 "A new field of scientific enquiry".

8 "Although it is attracting the interest of a growing number of researchers, research in this área is still fragmented, often mono-method and mainly descriptive and classificatory".

9 "The number of educational and training programmes tailored for social enterprises is also growing significantly".

10 "In all the countries studied, including those where social enterprises have grown in number and size and have proven to be efficient providers of a wide set of general interest services, management has remained an area of
} 
Presume-se que a relevância em desenvolver centros de treinamento e de pesquisa para a ESS em específico se justifica pelo fato de que "o apoio empresarial mainstream não tem sido eficaz em se envolver com empresas sociais, priorizando negócios comerciais mais tradicionais" (Ibid, tradução nossa) ${ }^{11}$. Assim como afirma o documento, a mera cópia de práticas dos empreendimentos tradicionais, "desconsidera o potencial das empresas sociais em desenvolver modelos alternativos mais eficientes e coerentes com suas raízes locais peculiares, dimensão inclusiva e objetivos sociais explícitos" (Ibid, tradução nossa) ${ }^{12}$. Além do que, isso auxiliará a ESS a desenvolver seus potenciais e consolidar o potencial como "uma alternativa verdadeira para as práticas insustentáveis atuais"13 (Ibid, tradução nossa).

No que se refere ao processo de construção de indicadores para a avaliação e monitoramento, o recente estudo dirigido por Monzon \& Chaves (2017), realizado em 28 países europeus, nos traz um importante salto no que concerne às informações quantitativas da ESS, até o ano de 2015. Tais informações referem-se ao número de ocupados em cooperativas, associações, mutualidades etc., bem como apresenta uma relação entre o total da ocupação em organizações da ESS e o total da ocupação na Europa que é em média 6,3\% Sobre esta informação, é interessante notar que há uma diferença notável entre os 28 países, uma vez que esta relação é em média de $1 \%$ em países como Lituânia (0,6\%), Croácia e Eslovênia (1\%), Malta (1,3\%) e Romênia (1,7\%), e de até $10 \%$ em países como Luxemburgo (9,9\%), Holanda $(9,8 \%)$, França $(9,1 \%)$ e Bélgica $(9 \%)$. Este estudo também traz o número de associados e de organizações, por tipo, entre os 28 países.

Um salto ainda maior foi dado pelo estudo - mesmo que de forma panorâmica e incipiente, o que revela, inclusive, o estágio embrionário do tema em âmbito internacional - no capítulo 8 do referido estudo, intitulado: "Métodos e indicadores para avaliar a economia social e seus impactos" (MONZON \& CHAVES, 2017, tradução nossa) ${ }^{14}$. Segundo o estudo:

Há um interesse crescente em estatísticas sobre a economia social. No entanto, dado que a economia social é um conceito relativamente novo no campo das estatísticas nacionais, enfrenta muitos desafios. Entre eles estão a identificação da população estatística, bem como o uso de metodologias e indicadores apropriados. Dito isto, a atual produção de estatísticas da economia social consegue transmitir certos aspectos do produto da economia social (...). São necessárias estatísticas sobre a economia social para quantificar o peso relativo deste tipo de economia, superar a sua falta de visibilidade e melhorar o conhecimento global e o reconhecimento do campo. A quantificação e a avaliação são passos cruciais para obter uma melhor compreensão da economia social e do seu lugar e papel. As estatísticas também têm uma função pragmática, na medida em que permitem o desenvolvimento e a avaliação de políticas públicas relativas à economia

weakness. This is mainly due to the fact that many social enterprises developed from community groups. Consequently, they are still staffed, to a significant extent, by volunteers, or they may not have the ability to recruit staff to meet specific managerial skills."

11 "mainstream business support has not been effective in engaging with social enterprises, instead prioritising more traditional commercial businesses”.

12 "disregards the potential of social enterprises to develop alternative models that are more efficient and consistent with their peculiar local roots, inclusive dimension and explicit social aims".

13 "a true alternative to current unsustainable mainstream economic practices".

14 "Methods and indicators to evaluate the social economy and its impacts". 
social em diferentes níveis territoriais, nacionais e internacionais. ${ }^{15}$ (MONZON; CHAVES, 2017, p. 92, tradução nossa).

Ainda conforme o estudo, a primeira tarefa em qualquer produção de estatística é definir o "objeto" ou os "seres" que serão medidos. No caso da ESS, há que se identificar as "entidades" que fazem parte deste "setor", bem como verificar a existência (ou não) de marco legal e, se tais atividades constam ou não nas Contas Nacionais dos respectivos países. Como tal "setor" é permeado por indefinições conceituais e teóricas, ou seja, pela ausência de consenso em suas definições, um conjunto de cinco critérios pode ser usado para distinguir as "entidades" que pertencem ou não ao campo da ESS. São eles: (i) a missão social (um princípio que anula todos os outros critérios); (ii) a distribuição limitada ou proibida de excedentes, que se manifesta principalmente na personalidade jurídica de uma organização (cooperativa, mutualidades, associação, fundação), ou pela presença de tal restrição no estatuto social; (iii) a presença de funcionários assalariados e/ou voluntários; (iv) o processo decisório da organização e, (v) a existência ou não de "governança democrática" (envolvendo o direito das partes interessadas, tais como usuários, trabalhadores, membros etc. - para supervisionar as decisões na organização.

Ademais, os métodos de triagem podem ser aplicados de várias formas (não exclusivas), a saber: seleção baseada em dados administrativos; seleção baseada em registros mantidos pelo governo - estes dois primeiros métodos, no caso europeu, ligados à elaboração das Contas Satélites da ESS; validação de dados elaborados e atualizados por redes da ESS (ou criação de Observatórios da ESS), bem como o uso de questionários específicos. No entanto, a escolha dependerá do grau de institucionalização do "setor" em cada país e dos consequentes avanços na elaboração de materiais quantitativos a respeito.

Em termos gerais, sobre esta importantíssima temática, de quantificação da ESS, notase que, no atual momento, uma das questões na produção de estatísticas é que a definição operacional varia entre países e poucos possuem registros em suas contas estatísticas. Nos últimos anos, reconhece-se a realização de um trabalho considerável para mapear a ESS que, no entanto, resultou na produção de uma variedade de noções e tipos de ESS, com diversas metodologias para calcular o peso da ESS no PIB, no total do emprego etc. Isso reflete a diversidade econômica, política e ideológica da ESS, para além da complexa e árdua dificuldade de conceituação e definição sobre o "setor". Indubitavelmente, constitui, também, uma das mais relevantes temáticas para a ESS no século XXI; tema este que deverá ser abordado em artigo específico.

\section{b. O CASO ASIÁTICO}

Em se tratando da construção do ecossistema empreendedor na Ásia, destaca-se o exemplo da Coreia do Sul, a partir do Local Social Economic Ecosystem Development Project (LSEEDP), criado para garantir a sustentabilidade da ESS sul-coreana. De acordo com Kim e Jung (2016, p. 40):

\footnotetext{
15 "There is a growing interest in statistics about the social economy. However, given that the social economy is a relatively new concept in the field of national statistics, it faces many challenges. Among these are the identification of the statistical population as well as the use of appropriate methodologies and indicators. That said, the current production of social economy statistics does succeed in conveying certain aspects of the output of the social economy (...) Statistics on the social economy are needed in order to quantify the relative weight of this type of economy, counteract its lack of visibility and improve overall knowledge and recognition of the field. Quantification and evaluation are crucial steps for gaining a better understanding of the social economy and its place and role. Statistics also have a pragmatic function in that they allow development and assessment of public policy concerning the social economy at different territorial, national and international levels."
} 
Os objetivos são fortalecer a cooperação interna e o trabalho em rede entre os atores da economia social local e, assim, induzir um ecossistema saudável e próspero da economia social, baseado na cooperação entre todos. Projetos estratégicos locais têm como objetivo garantir a incorporação da economia social nas comunidades locais. ${ }^{16}$ (KIM; JUNG, 2016, p. 40, tradução nossa).

No caso sul-coreano, a estrutura desenvolvida contempla os governos locais (com suas respectivas políticas de apoio), as redes de ESS (e seus centros de cooperação) e a sociedade civil (consultada em suas instâncias participativas). Neste ecossistema, a "formação de ativos" (em temas de infraestrutura, recursos humanos e expansão de mercado) é tida como elemento fundamental e todo esse processo desagua nos "projetos locais estratégicos", onde se concebem projetos de apoio à incubação de empreendimentos de ESS e de desenvolvimento local. Embora integrados, o LSEEDP prioriza os projetos de desenvolvimento local a partir dos "ecosystem groups for boroughs" (espécie de grupos ecossistêmicos de bairro), que são apoiados por até cinco anos, até que atinjam níveis de autonomia. Esse processo se divide em duas etapas, sendo a primeira de fomento às capacidades da sociedade civil (leia-se dos "bairros" selecionados) e a segunda de assistência a temas econômicos, financeiros, jurídicos etc. dos potenciais empreendimentos iniciados.

Outro aspecto interessante refere-se à criação das "Zonas de Economia Social” ("Social Economy Zone" - SEZ) com o intuito de "permitir que cada bairro identifique e faça uso estratégico dos recursos locais disponíveis para compartilhamento, a fim de resolver problemas locais por meio da cooperação local" 17 (KIM; JUNG, 2016, p. 49, tradução nossa). Como exemplos de zonas já criadas, citam-se a Social Fashion Ecosystem Development Project na região de Seongdong e o Local Social Service Center em Seongbuk, além das zonas ligadas ao desenvolvimento de novos modelos de empreendedorismo social na área do turismo, da arte e da cultura, como os desenvolvidos em Mapo e os de atividades de reciclagens em Nowon.

Vale registrar que a ideia e as ações voltadas ao fortalecimento do ecossistema empreendedor solidário em Seoul são parte do Seoul's Social Economy Policy (2011-2015), com o claro objetivo de "promover um ecossistema para maior autossuficiência" ${ }^{18}$ (tradução nossa). Neste período, o programa destinou 50 bilhões de KRW (won sul-coreano) (equivalente a cerca de USD 45 milhões, em valores de 2017) para o Seoul Social Investment Fund realizar seus projetos (KIM; JUNG, 2016).

\subsection{O ECOSSISTEMA EMPREENDEDOR PARA A ESS NO BRASIL: AVANÇOS, RETROCESSOS E DESAFIOS}

Antes de tratar especificamente o caso brasileiro, cabem algumas considerações mais gerais sobre a América Latina. Nesta região, um recente estudo sobre o cooperativismo e a ESS nos mostra uma crescente importância das políticas públicas para o fortalecimento do setor, com atenção às suas conexões com o desenvolvimento local, inclusão social e práticas de resiliência em territórios vulneráveis - social, econômica e politicamente - como é o caso da Colômbia, por exemplo, que enfrentou o processo de pacificação, a partir de geração de oportunidades via ESS. Os estudos apontam também para a importância em se constituir bases

\footnotetext{
16 "The goals are to strengthen internal cooperation and networking among actors of the local social economy, and thereby to induce a healthy and thriving social economy ecosystem based on their cooperation. Local strategic projects are intended to ensure the embedding of the social economy in local communities. "

17 "allows each borough to identify and make strategic use of local resources available for sharing in order to solve local problems through local cooperation".

18 "fostering an ecosystem for greater self-sufficiency".
} 
de fortalecimento para a sociedade civil, não somente em termos econômicos, mas também no que diz respeito a geração de capacidades para a coesão social e a governança democrática. Em termos microeconômicos, os estudos por países demonstraram uma ampliação da atenção em temas de sustentabilidade financeira dos EES, assim como nas práticas de cooperação e de estabelecimento de redes entre as cooperativas e os EES em geral; práticas estas que vêm sendo sistematizadas com mais frequência e rigor metodológico. Como interessante exemplo, cita-se o caso do Equador e as inovações com base na experiência das redes de produtores orgânicos; experiência esta que também se verifica em Cuba, Costa Rica, Paraguai etc. (BAJO, 2017).

Quanto à questão do constructo do ecossistema empreendedor solidário, é interessante notar que o estudo chama atenção ao fato de que algumas experiências de êxito na constituição de cooperativas na região se dão em segundo plano, uma vez que o ponto de partida está nos processos de "community participation". Segundo Bajo (2017):

[...] as cooperativas aparecem depois que as comunidades começam a participar, até certo ponto, no processo de construção de sua própria cidadania, sua inclusão em um processo de co-construção de normas e práticas, levantando a dúvida em saber se as cooperativas são resultado de uma consciência crescente sobre necessidades comuns, bem como capacidades recém-descobertas - neste sentido, carregadas nos ombros dos movimentos sociais $^{19}$ (BAJO, 2017, p. 7, tradução nossa).

Ainda referindo-se aos elementos do ecossistema para a América Latina, vale registrar que, de acordo com Vuotto (2017), a pertinente temática da mensuração e da avaliação e monitoramento das atividades dos EES também é tratada em estudos mais recentes. Na visão da autora: "[...] outras formas de abordar o conhecimento que podem ser encontradas nos estudos incluem sistematização e avaliação [...], a avaliação produz informação para a tomada de decisão como meio de otimizar a gestão do projeto"20 (VUOTTO, 2017, p.22, tradução nossa).

No Brasil, o termo ESS não encontra consenso, apesar das organizações que atuam na interface entre a economia e a sociedade constituírem um fenômeno social expressivo e cada vez mais reconhecido. Já no que diz respeito à esfera da práxis, percebe-se uma ampla gama de atores e formas jurídicas que constituem este campo, sendo as cooperativas as mais fáceis de distinguir e com maior tradição em nosso país.

Tratando-se especificamente da "Economia Solidária" (ESOL), no país, o início da institucionalização tem como marco formal o surgimento da Secretaria Nacional de Economia Solidária (SENAES), em 2003, muito embora, seu surgimento advenha de movimentos sociais e políticos, bem como de experiências prévias à sua criação ${ }^{21}$.

Desde seu surgimento, em 2003, até o ano de 2016, quando teve início um retrocesso nas políticas para a ESOL, culminando em sua extinção em 2019, a Secretaria, a partir do "Programa Economia Solidária em Desenvolvimento", inseriu-se, paulatinamente, nos Planos Plurianuais do Governo Federal (2004-2007; 2008-2011; 2012-2015), constituindo o início do processo de institucionalização da política pública de ESS no país, ou seja, de um

\footnotetext{
19 “[...] cooperatives appear after communities begin taking part, to some degree, in the process of building their own citizenship, their own inclusion into a process of co-construction of norms and practices, raising the question of whether cooperatives are a result of increased consciousness regarding common needs as well as newly discovered capacities - in this sense carried on the shoulders of social movements".

20 "[...] other ways of approaching knowledge that can be found in studies include systematization and

evaluation [...] evaluation produces information for decision-making as a means to optimize project management".

${ }^{21}$ Para uma avaliação mais detalhada consultar Morais (2013).
} 
marco jurídico da Economia Solidária em construção. Houveram também estratégias de expansão das políticas públicas estaduais e municipais de Economia Solidária, assim como o surgimento dos Centros Públicos de Economia Solidária e da Frente Parlamentar da Economia Solidária. Importante também foram o surgimento e o fortalecimento das Conferências Nacionais de Economia Solidária e do Conselho Nacional de Economia Solidária. Do ponto de vista econômico, o "setor" 22 representa cerca de $8 \%$ do Produto Interno Bruto (PIB) nacional e dois milhões de postos de trabalho.

No que se refere à quantificação dos EES, o último mapeamento nacional de ESOL foi realizado e publicado em "A Economia Solidária no Brasil: uma análise dos dados nacionais", sob a coordenação de Gaiger (2014). Tal mapeamento pode servir como caracterização da ESOL no Brasil após treze anos de políticas públicas realizadas pela SENAES. Com base nesse mapeamento, há 19.708 EES e 1.423.631 associados. Destes, quase 55\% estão na área rural, enquanto 34,8\% estão na área urbana e 10,4\% dos EES atuam simultaneamente no espaço rural e urbano. Por regiões do Brasil, $41 \%$ dos EES estão no Nordeste, $17 \%$ no Sul, $16 \%$ estão no Norte, sendo a mesma cifra no Sudeste e $10 \%$ no Centro-Oeste. Quanto à forma de organização dos EES, nota-se uma ampla predominância das associações, com 60\% dos EES, 30,5\% de grupos informais, $9 \%$ de cooperativas e menos de $1 \%$ sociedades mercantis.

No entanto, a despeito das potencialidades e avanços na ESOL no Brasil, percebe-se que este "setor" é marcado por determinadas fragilidades. Conforme Morais \& Bacic (2016) tais fragilidades situam-se, em:

a. Fragilidades microeconômicas: condições de mercado (oferta e demanda dos produtos e serviços), fixação de preços e de custos produtivos, condições de comercialização, acesso à tecnologia, ao capital de giro dos empreendimentos etc. ${ }^{23}$;

b. Fragilidades macroeconômicas: condições mais gerais de funcionamento da economia e da exclusão de determinados grupos de acesso ao crédito em condições facilitadas; taxa de juros elevadas; impactos do aperto fiscal na continuidade de programas, projetos e ações etc.;

c. Políticas públicas de apoio: a falta de ações integradas e transversais (entre ministérios, secretarias etc., nos âmbitos federal, estadual e municipal) que arrefecem potenciais avanços em prol dos objetivos de geração de trabalho, emprego e renda e da própria existência de diversas experiências. Isto se deve também à falta de clareza no que concerne à definição e mensuração do "setor".

Assim, reitera-se que a existência e o fortalecimento do ecossistema empreendedor solidário se projetam como um importante aliado no enfrentamento destas fragilidades intrínsecas à ESOL (MORAIS; BACIC, 2018).

Em 2017, foi dado um passo importante na direção da institucionalização da política pública de ESOL no país, com a aprovação, pela Comissão de Constituição e Justiça (CCJ) da Câmara, do Projeto de Lei 4685/12, que cria o Sistema Nacional da Economia Solidária ${ }^{24}$. No entanto, entende-se que a estrutura ecossistêmica vai além da questão do marco legal, que, por si só, é de extrema relevância.

\footnotetext{
${ }^{22}$ Informações adicionais em: http://easycoop.com.br/Revista/View.aspx?IDC=[idc]\&ID=289

${ }^{23}$ Sobre aspectos da produção e comercialização dos EES, consultar Morais \& Bacic (2016).

24 Em março de 2019 o projeto estava em tramitação no Senado: (https://www25.senado.leg.br/web/atividade/materias/-/materia/131528)
} 
Nesta perspectiva, ainda que em momentos de crise econômica e fiscal, a construção do ecossistema empreendedor, embora sem uma estrutura claramente definida, pode ser visualizado a partir de algumas ações, projetos e programas.

O Quadro 1, a seguir, foi elaborado com base nos componentes anteriormente descritos que sugerem uma estrutura para o constructo do ecossistema europeu para a ESOL. Esse exercício permitiu verificar que no Brasil já há sementes dessa estrutura, embora ela não seja formalizada.

\section{Quadro 1 - Estado da arte do ecossistema empreendedor para a ESOL no Brasil}

a) Conhecimento - sensibilização política e formas legais de reconhecimento destas políticas e ação: SENAES;

b) Acesso aos mercados: Programa de Aquisição de Alimentos (PAA); Programa Nacional de Alimentação Escolar (PNAE); Feiras de Economia Solidária; Política Nacional de Resíduos Sólidos;

c) Suporte público e fiscal para start-ups de ESS: Editais SENAES (Ex. Projeto Redes);

d) Acesso ao financiamento: Financiadora de Projetos do Governo Federal (FINEP), Banco Nacional da Bahia (BHB), Banco Nacional de Desenvolvimento Econômico e Social (BNDES), microcrédito, fundos rotativos solidários, bancos comunitários (Ex. Palmas, Cocais etc.);

e) Instrumentos de apoio às redes e suporte mútuo: Fórum Brasileiro de Economia Solidária (FBES); Conselho Nacional de Economia Solidária (CONAES); Projeto Redes;

f) Desenvolvimento de pesquisas e de qualificação na área: Incubadoras Tecnológicas de Cooperativas Populares (ITCPs), Rede da incubadoras públicas de empreendimentos solidários da UNITRABALHO; Centros de Estudos - Análises de ESS formais e informais;

Fonte: Elaboração própria com base em European Commission (2016)

De maneira geral, o Quadro 1 nos mostra que, do ponto de vista da política pública e da participação da sociedade civil, são importantes o Fórum Brasileiro de Economia Solidária (FBES), a criação da SENAES, em 2003, e seus diversos projetos e ações.

Outras "sementes" do ecossistema no país são:

a) as universidades que, ainda que em momentos difíceis, são apoiadas financeiramente pelo governo federal (por editais ou projetos), para atuarem como incubadoras de empreendimentos de ESS a partir das ITCPs - Incubadoras Tecnológicas de Cooperativas Populares. Há, inclusive, alguns governos municipais e estaduais que apresentam projetos e ações na área. Também há a Rede de incubadoras públicas de empreendimentos solidários da UNITRABALHO;

b) bancos que atuam com o microcrédito e ou com moedas sociais. Tais bancos comunitários são uma realidade em alguns municípios no país, e contabilizam uma rede de mais de 100 bancos comunitários (como o originário Banco Palmas);

c) financiamento da SENAES (embora no momento extremamente restrito e até paralisado) para projetos específicos como o Projeto Redes (de fomento de redes de EES finalizado em 2016 e na espera de renovação), projetos para a cadeia de reciclagem etc.; 
d) programas de garantia de demanda (acesso ao mercado) como o PAA e PNAE, citados no Quadro 1, que permitem a compra pública sem licitação de alimentos de EES, fundamentalmente, de pequenos produtores rurais;

e) existência de redes de EES, formais e informais, bem como de importantes instituições de apoio, discussão e força política para a ESS como o FBES e o CONAES supramencionados;

f) ampla e crescente base de estudos sobre ESS nas universidades em cursos de graduação e de pós-graduação (sobretudo em cursos de economia, ciências sociais etc.), seja em disciplinas de qualificação na área, seja em trabalhos de conclusão de graduação ou pósgraduação (especialização, mestrado e doutorado). Basta verificar os dados mencionados em Icaza (2017), que aponta para um significativo crescimento de estudos nas áreas do cooperativismo e da ESS, nas duas últimas décadas;

g) avanços na elaboração de Conselhos Municipais de ESOL e de Leis Municipais de ESOL, como nos casos dos municípios de Araraquara (SP), de Balneário Camboriú (SC) etc.

No entanto, a partir de 2016, no governo Temer, as políticas públicas em apoio à ESOL tiveram um retrocesso, que foi ainda mais intensificado em 2019, com o início do governo Bolsonaro. Durante o governo Temer a SENAES foi transformada em Subsecretaria do Ministério do Trabalho e teve os fundos diminuídos, o que restringiu suas possibilidades de atuação. Já no governo Bolsonaro o Ministério do Trabalho foi extinto e parte de suas atribuições remetidas ao Ministério da Cidadania (medida provisória 870/2019). No artigo 23 são definidas as competências desse ministério, entre elas "XXIV - cooperativismo $e$ associativismo urbanos". O artigo $24^{\circ}$ da mesma MP informa a estrutura desse ministério e indica a existência de "XV - o Conselho Nacional de Economia Solidária". E diz: " $\$ 3$ - O Conselho Nacional de Economia Solidária é órgão colegiado de composição tripartite, observada a paridade entre representantes dos trabalhadores e dos empregadores, na forma estabelecida em ato do Poder Executivo federal". Cabe perguntar quem o governo identifica como empregadores dentro da ESOL.

O Decreto $\mathrm{N}^{\circ}$ 9.674, de 2 de janeiro de 2019, define no artigo $2^{\circ}$ as Secretarias e Departamentos do Ministério da Cidadania. Dentro da Secretaria Nacional de Inclusão Social e Produtiva Urbana figura o Departamento de Economia Solidária. Esta nova estrutura evidencia a extinção da SENAES e a alteração da concepção das políticas "associando a Economia Solidária, às políticas de inclusão social e produtiva da assistência social e limitando seu público ao setor urbano" (PINHO, 2019, p.1). O associativismo rural foi remetido para o Ministério de Agricultura dentro da Secretaria de Agricultura Familiar e Cooperativismo. Desta forma, as políticas mais amplas de associativismo e economia solidária foram fragmentadas e os trabalhadores rurais, que se organizam por meio da autogestão, foram excluídos, nos termos desse decreto, da ESOL.

Os fatos acima expostos mostram que a conclusão de uma arquitetura favorável para um ecossistema dedicado aos EES está em risco. Nesta conjuntura falta, ainda, concluir um contexto legal para a ESS, com uma legislação clara e pertinente; aprimorar a atuação dos agentes de forma a reconhecer as limitações e especificidades dos EES e desenhar políticas e ações coerentes para sua superação; assim como avançar na criação de indicadores de avaliação e de monitoramento dos EES. No atual contexto político e legal estas tarefas faltantes dificilmente serão realizadas.

\section{CONSIDERAÇÕES FINAIS}


A formação do ecossistema empreendedor para a ESS é peça fundamental para a emancipação e o fortalecimento dos EES, tendo em vista as fragilidades estruturais inerentes ao seu modus operandi.

Conforme se tentou mostrar, entende-se como uma estrutura coerente de organização do processo ecossistêmico empreendedor solidário, os seguintes componentes: a) Conhecimento; b) Acesso aos mercados; c) Suporte público e fiscal para start-ups de ESS; d) Acesso ao financiamento; e) Instrumentos de apoio às redes e suporte mútuo e, f) Desenvolvimento de pesquisas e de qualificação na área. Reitera-se que é importante incluir nesta estrutura a capacidade de se criar indicadores de avaliação e monitoramento dos EES; tarefa árdua e complexa, porém de extrema relevância para avaliar as políticas relacionadas a ESS.

Para além desta estrutura de composição ecossistêmica, vale frisar o papel fundamental dos seguintes atores, bem como seus esforços e responsabilidades de construção conjunta: os EES, a universidade e a participação na construção conjunta da política pública. Adicionalmente, crê-se que a manutenção da liderança do ecossistema dependerá da capacidade de convencimento dos seus atores de que vale a pena continuar evoluindo em conjunto, ou seja, coevoluindo. Em outros termos, a vitalidade coletiva (e não individual) do ecossistema é condição de sua própria sustentabilidade, manutenção e evolução. Ao invés de focar apenas nas suas competências, recursos e capacitações internas, os envolvidos devem saber das interdependências entre os organismos dos ecossistemas e enfatizar as propriedades coletivas das redes de EES.

Daí deriva-se que outro elemento fundamental da construção ecossistêmica é o grau de interconectividade; de interdependência que todos os componentes do sistema guardam entre si, bem como a necessidade da construção de um processo que se deve permear por uma perspectiva "bottom-up" e de transversalidade, possibilitando a coevolução na direção de uma "vitalidade coletiva" e com graus de interconectividade.

Em termos práticos, já, há exemplos em alguns lugares do mundo que podem nos auxiliar e inspirar, tais como os casos europeus, asiáticos e latino-americanos tratados.

No que concerne ao caso brasileiro, a despeito das potencialidades e avanços na ESOL, percebe-se que este "setor" é marcado por determinadas fragilidades, referidas anteriormente. Tais fragilidades situam-se, fundamentalmente, em: a) Fragilidades microeconômicas: condições de mercado (oferta e demanda dos produtos e serviços), fixação de preços e de custos produtivos, condições de comercialização, acesso à tecnologia, ao capital de giro dos empreendimentos etc.; b) Fragilidades macroeconômicas: condições mais gerais de funcionamento da economia e da exclusão de determinados grupos de acesso ao crédito em condições facilitadas; taxa de juros elevadas; impactos do aperto fiscal na continuidade de programas, projetos e ações etc. e, c) Políticas públicas de apoio: falta de ações integradas e transversais (entre ministérios, secretarias etc., nos âmbitos federal, estadual e municipal) que arrefecem potenciais avanços em prol dos objetivos de geração de trabalho, emprego e renda e da própria existência de diversas experiências. Isto se deve também à falta de clareza no que concerne à definição e mensuração do "setor".

Assim, reitera-se que a existência e o fortalecimento do ecossistema empreendedor solidário se projetam como um importante aliado no enfrentamento dessas fragilidades intrínsecas à ESOL.

Em 2017, um passo importante foi dado na direção da institucionalização da política pública de ESOL no país, com a aprovação do Projeto de Lei 4685/12, que cria o Sistema Nacional da Economia Solidária. No entanto, entende-se que a estrutura ecossistêmica vai além da questão do marco legal, que, por si só, é de extrema relevância. Além do que, o atual momento político e econômico é de apreensão para o fortalecimento do ecossistema 
empreendedor solidário no país, tendo em vista os cortes no financiamento das políticas públicas da ESOL (SENAES) e as indefinições de projetos e de ações na própria SENAES, a partir do Governo Temer (2016 e 2018) e a extinção da SENAES em 2019 (Governo Bolsonaro) que criou em seu lugar, o Departamento de Economia Solidária, no Ministério da Cidadania.

Espera-se que este cenário nebuloso se altere no futuro, de modo a fortalecer as ricas e frutíferas experiências da ESS no país, que dialogam com a criação de trabalho, emprego e renda por meio de milhares de EES ao longo do Brasil e, consequentemente dinamizam a economia, mas que também incluem em seu âmago, aspectos do desenvolvimento local e comunitário, governança democrática e empoderamento de grupos desfavorecidos. Dada a capilaridade dos EES e sua característica inerente de surgimento endógeno, a partir da experiência dos setores populares, é certo que estas experiências continuarão surgindo e se desenvolvendo ao longo do território do país, de forma independente ao maior ou menor apoio das políticas do governo federal.

\section{REFERÊNCIAS BIBLIOGRÁFICAS}

BACIC, M. Da oportunidade de pensar no desenvolvimento de um ecossistema empreendedor para os empreendimentos de economia solidária em América Latina. Publicações da $4^{a}$ Academia Internacional sobre Economia Social e Solidária da OIT - Campinas, 2014. ILO, Genebra, 2014

BAJO, C. Research on cooperatives in Latin America, an overview of the state of the art and contributions. Review of International Co-operation. International Co-Operative Alliance, volume 104, p. 3-13, 2017

BRÄNNBACK, M. et al. Challenging the triple helix model of regional innovation systems: A venture-centric model. International Journal of Technoentrepreneurship, v.1, n. 3, p.257$277,2008$.

COHEN, B. Sustainable Valey Entrepreneurial Ecosystems, Business Strategy and the Environment., vol. 15 (1), 1-14, 2006.

ETZKOWITZ, H.; LEYDESDORFF, L. The triple helix university industry government relations: a laboratory for knowledge based economic development. European Association Study Science and Technology Review, London, v. 14, n. 1, p. 14-19, 1995.

EUROPEAN COMMISSION. Social enterprises and their eco-systems: developments in Europe. Luxemburgo, 2016. Disponível em: <https://ec.europa.eu/social/BlobServlet?docId=16376\&langId=en>. Acesso em 12 out. 2018

GAIGER, L. A dimensão empreendedora da economia solidária: Notas para um debate necessário. Outra Economia - V. II - No 3 - 2º 2008.

GAIGER, L. (Org). A Economia Solidária no Brasil: uma análise de dados nacionais. Editora OIKOS, 2014.

IANSITI, M.; LEVIEN,R. Strategy as Ecology. Harvard Business Review, march, 2004.

ICAZA, A . Status, advancements, and challenges for the research on cooperatives in Brazil. In: Review of International Co-operation. International Co-Operative Alliance, volume 104, p. 25-32., 2017. 
KANTIS, H. Surgimiento y desarrollo de ecosistemas: una mirada evolutiva sobre dos casos emblemáticos. In: Programa de Desarrollo Emprendedor (PRODEM). Brief no. 1, Parte A, setembro de 2017.

KIM, Y.; JUNG, T. Status of Social Economy Development in Seoul: a Case Study of SeouI. GSEF Social Economy Policy Guidebook - Seoul Metropolitan Government, 2016.

LEMOS, P. As Universidades de Pesquisa e a Gestão Estratégica do Empreendedorismo Uma proposta de metodologia de análise de ecossistemas. Campinas: Instituto de Geociências - UNICAMP (Tese de Doutorado), 2011.

MONZON, J.; CHAVES, R. (org) Recent evolutions of the Social Economy in European Union. In: European Economic and Social Committee, CIRIEC-International - Centre international de recherches et d'information sur l'économie publique, sociale et cooperative. Bruxelas, 2017.

MORAIS, L. As políticas públicas de Economia Solidária (ESOL): avanços e limites para a inserção sociolaboral dos grupos-problema. Campinas: IE-UNICAMP (Tese de Doutorado), 2013.

MORAIS, L.P.; BACIC, M. Redes de Economia Solidária e a relevância do ecossistema empreendedor solidário. In: V Simpósio Internacional Desigualdades, Direitos e Políticas Públicas e I Conferência Internacional RILESS-EMES: Economia Solidária e Empresas Sociais. UNISINOS, 2016.

MORAIS, L.; BACIC, M. Modern cooperatives in the system of sustainable development goals: the importance of the solidarity entrepreneurship ecosystem. In: Journal Fundamental \&amp; applied researches of coop sector of economics. Moscow, Dec., no. 6., 2018.

PINHO, L. Qual é o Ano Novo para a Economia Solidária no novo Governo?. CEFURIA, 2019. Disponível em: <http://www.cefuria.org.br/2019/02/14/artigo-qual-e-o-ano-novo-paraa-economia-solidario-no-novo-governo/>. Acceso em: 12 marco 2019

SERVIÇO BRASILEIRO DE APOIO ÀS MICRO E PEQUENAS EMPRESAS - SEBRAE. Sobrevivência das empresas no Brasil. / Marco Aurélio Bedê (Coord.) - Brasília, 2016.

SERRANO, S. Economía social y solidaria: una propuesta para un ecosistema más complejo. In: Información Estadística y Cartográfica de Andalucía. España, no. 5, p. 172-178., 2015.

SPILLING. The Entrepreneurial system: on entrepreneurship in the context of a mega-event. Journal of Business Research, 36, p. 91-103, 1996.

VUOTTO, M. Content and scope of research on cooperatives: the performance of the Latin American Network of researchers on cooperatives. In: Review of International Co-operation. International Co-Operative Alliance, volume 104, p. 14-25, 2017.

Recebido em 02 de março de 2018 Aceito em 10 de março de 2019 